\title{
Diagnosis of Wilson's disease: an experience over three decades
}

\author{
P J Gow, R A Smallwood, P W Angus, A L Smith, A J Wall, R B Sewell
}

\begin{abstract}
Background-Wilson's disease is a rare but treatable condition that often presents diagnostic dilemmas. These dilemmas have for the most part not been resolved by the identification and cloning of the Wilson's disease gene.

Aims-To report our experience over three decades with patients with Wilson's disease in order to illustrate the diverse patterns of presentation and thereby broaden the approach to diagnosis.

Methods-Clinical and laboratory findings of 30 patients with Wilson's disease were reviewed.

Results-Twenty two patients presented with liver manifestations (eight with fulminant hepatic failure and 14 with chronic liver disease), three with neurological disease, and one with haemolysis; four were asymptomatic siblings of patients with Wilson's disease. Seventy per cent were diagnosed within six months of the onset of symptoms, but diagnosis was delayed for up to nine years. Age range at diagnosis was wide (7-58 years) and five patients were over 40 . In patients presenting with non-fulminant disease, $18 \%$ had neither Kayser-Fleischer rings nor low caeruloplasmin concentrations. Increased liver copper concentrations were found in all but one patient who had undergone six years of penicillamine treatment. In fulminant hepatic failure $(n=8)$ additional features helpful in the diagnosis included evidence of haemolysis, increased urinary copper (range 844-9375 $\mu \mathrm{g} / 24 \mathrm{~h}$ ), and a high non-caeruloplasmin copper (range 325-1743 $\mu \mathrm{g} / 1)$.
\end{abstract}

Conclusions-The diagnosis of Wilson's disease still depends primarily on the evaluation of clinical and laboratory evidence of abnormal copper metabolism. No one feature is reliable, but the diagnosis can usually be made provided that it is suspected. Wilson's disease should be considered in patients of any age with obscure hepatic or neurological abnormalities. (Gut 2000;46:415-419)

Keywords: Wilson's disease; diagnosis; liver; fulminant hepatic failure

Wilson's disease, first described by Kinnear Wilson in 1912, is an autosomal recessive condition with a prevalence in most populations of one in $30000 .{ }^{1}$ It is clinically characterised by hepatic and neurological manifestations related to the accumulation of copper in the liver and the lenticular nuclei, and by Kayser-Fleischer rings. In 1993 the Wilson's disease gene was identified and its structure elucidated. ${ }^{23} \mathrm{Ap}-$ proximately 70 individual mutations have been identified in patients with Wilson's disease, ${ }^{4} \mathrm{a}$ phenomenon which may in part explain the clinical heterogeneity of the disease. ${ }^{5}$ Due to the number of individual mutations, a diagnosis based on DNA studies and identification of mutations is not practicable for most laboratories, so that clinicians still have to rely on standard clinical and laboratory criteria.

Establishing the diagnosis of Wilson's disease is usually straightforward if the major clinical and laboratory features are present: typical hepatic and/or neurological symptoms and signs, Kayser-Fleischer rings, low serum caeruloplasmin concentrations, and increased urinary copper excretion. However, in patients who present with liver disease alone, KayserFleischer rings are often absent and serum caeruloplasmin concentrations may be normal. ${ }^{5}$ Diagnosis has an added difficulty in fulminant hepatic failure, as serum caeruloplasmin may be low and urinary copper excretion high in patients who do not have Wilson's disease. ${ }^{6}$ Asymptomatic siblings of patients with Wilson's disease, in whom the diagnosis needs to be confirmed or ruled out, can also present diagnostic uncertainties. ${ }^{7}$

In this paper our experience of 30 patients with Wilson's disease cared for over three decades is reported, with particular emphasis on disease presentation and the difficulties involved in diagnosis.

\section{Patients and methods}

Clinical and laboratory data were obtained from a review of the files of patients presenting from 1971 to 1998 at the Austin and Repatriation Medical Centre, Royal Children's Hospital and Royal Melbourne Hospital. All patients were cared for by one of the authors. The Austin and Repatriation Medical Centre is a tertiary referral hospital with a catchment population of 750000 and serves as the only centre for liver transplantation in the states of Victoria and Tasmania (population five million). Liver transplantation began at this institution in November 1988. The Royal Children's Hospital is the primary specialist paediatric hospital servicing the state of Victoria.

The principal criteria used to establish a provisional diagnosis of Wilson's disease were hepatic and/or neurological clinical abnormalities

Abbreviations used in this paper: ALP, alkaline phosphatase; ALT, alanine aminotransferase. 
Table 1 Patient details: non-fulminant presentation

\begin{tabular}{|c|c|c|c|c|c|c|c|c|}
\hline Patient no & $\begin{array}{l}\text { Age at } \\
\text { diagnosis (y), } \\
\text { sex }\end{array}$ & Mode of presentation & $\begin{array}{l}\text { Caeruloplasmin * } \\
(\mathrm{g} / \mathrm{l})\end{array}$ & $\begin{array}{l}\text { Liver coppert } \\
(\mu g / g)\end{array}$ & $\begin{array}{l}\text { Radiocopper } \\
\text { study }\end{array}$ & $\begin{array}{l}\text { Kayser-Fleischer } \\
\text { rings }\end{array}$ & $\begin{array}{l}\text { Urine copper } \neq \\
(\mu g / 24 h)\end{array}$ & Histology \\
\hline 1 & $7, \mathrm{~F}$ & Hepatic & 0.01 & 1171 & - & Absent & 362 & Fibrosis \\
\hline 2 & $9, \mathrm{~F}$ & Hepatic & 0.057 & $1201^{\mathrm{a}}$ & - & Present & 281 & Cirrhosis \\
\hline 3 & $9, M$ & Hepatic & 0.05 & 385 & - & Present & 862 & Fibrosis \\
\hline 4 & $9, M$ & Family history & 0.32 & 767 & - & Absent & 131 & CAH \\
\hline 5 & $11, M$ & Hepatic & Low $\S$ & 380 & - & Present & 221 & Cirrhosis \\
\hline 6 & $11, M$ & Hepatic & 0.12 & 795 & C/W WD & Present & 5 & Cirrhosis \\
\hline 7 & $12, \mathrm{M}$ & Neurological & Low $\$$ & 804 & - & Present & 4 & Cirrhosis \\
\hline 8 & $13, M$ & Hepatic & 0.176 & 546 & - & Present & 7 & Cirrhosis \\
\hline 9 & $14, \mathrm{~F}$ & Hepatic & 0.44 & 1787 & - & Present & $7000^{\mathrm{e}}$ & Cirrhosis/CAH \\
\hline 10 & $16, M$ & Hepatic & 0.35 & $799^{\mathrm{b}}$ & - & Present & $4812^{\mathrm{e}}$ & Cirrhosis \\
\hline 11 & $17, \mathrm{~F}$ & Neurological & Low $§$ & 680 & - & Present & 4 & Cirrhosis \\
\hline 12 & $19, M$ & Neurological & Low $§$ & 782 & - & Present & 5 & Cirrhosis \\
\hline 13 & $20, \mathrm{~F}$ & Hepatic & 0.06 & 1700 & - & Present & 150 & Fibrosis/CAH \\
\hline 14 & $22, \mathrm{M}$ & Haemolysis & 0.052 & 530 & C/W WD & Present & 1300 & $\mathrm{CAH}$ \\
\hline 15 & $23, M$ & Hepatic & Low $§$ & 306 & - & Present & $5676^{\mathrm{e}}$ & Fibrosis \\
\hline 16 & $27, M$ & Family history & Low\$ & 914 & - & Absent & 55 & Fibrosis \\
\hline 17 & $29, \mathrm{~F}$ & Family history & Low $\$$ & 831 & - & Absent & 2 & Fibrosis \\
\hline 18 & $30, \mathrm{~F}$ & Family history & Low $\$$ & 478 & - & Absent & 474 & Fibrosis \\
\hline 19 & $34, \mathrm{M}$ & Hepatic & 0.38 & $49^{c}$ & $\mathrm{C} / \mathrm{W}$ WD & Absent & 250 & Cirrhosis \\
\hline 20 & $45, \mathrm{M}$ & Hepatic & 0.30 & $634^{\mathrm{d}}$ & - & Absent & 2 & Cirrhosis \\
\hline 21 & $47, M$ & Hepatic & 0.15 & 516 & - & Present & 325 & Fibrosis/CAH \\
\hline 22 & $58, \mathrm{~F}$ & Hepatic & 0.37 & 1037 & $\mathrm{C} / \mathrm{W}$ WD & Absent & 44 & Fibrosis/CAH \\
\hline
\end{tabular}

*Normal caeruloplasmin $0.20-0.45 \mathrm{~g} / \mathrm{l}$; †normal liver copper $15-60 \mu \mathrm{g} / \mathrm{g}$ dry weight liver; łnormal urine copper less than $100 \mu \mathrm{g} / 24 \mathrm{~h}$; $\$$ caeruloplasmin quantitated in optical density units.

${ }^{a}$ Liver copper quantitated at time of transplantation 12 months after presentation; bliver copper quantitated at time of transplantation three years after presentation; cliver copper quantitated at time of transplantation six years after presentation; ${ }^{\mathrm{d}}$ liver copper quantitated at time of transplantation six months after presentation; ${ }^{\mathrm{e}}$ urine copper quantitated while on penicillamine therapy.

C/W WD, radiocopper study consistent with the diagnosis of Wilson's disease; CAH, chronic active hepatitis; FHF, fulminant hepatic failure.

consistent with the diagnosis, the presence of Kayser-Fleischer rings, a low serum caeruloplasmin concentration (less than $0.20 \mathrm{~g} / 1^{8}$ ), and a raised 24 hour urine copper excretion (greater than $\left.100 \mu \mathrm{g} / 24 \mathrm{~h}^{8}\right)$. The diagnosis was confirmed by the finding of a high liver copper concentration (greater than $250 \mu \mathrm{g} / \mathrm{g}$ dry weight of liver $\left.{ }^{8}\right)$. Plasma disappearance of ${ }^{64} \mathrm{Cu}$ provided further diagnostic assistance in four patients in whom the diagnosis remained uncertain. In patients with Wilson's disease there is no secondary increase in radiocopper concentration in the circulation, reflecting abnormal incorporation of copper into caeruloplasmin. ${ }^{9}$ In patients with fulminant hepatic failure, the serum non-caeruloplasmin copper concentration was estimated (normal less than $375 \mu \mathrm{g} / \mathrm{l}^{10}$ ).

Liver function tests and other routine laboratory data were obtained using standard methods. Serum caeruloplasmin was measured in most patients by an immunoprecipitation method $^{11}$ and in 10 patients on the basis of its oxidase activity. ${ }^{12}$ Liver copper concentration in dried liver tissue was measured by flame atomic absorption spectroscopy. ${ }^{13}$ Liver biopsy specimens were obtained for analysis of copper concentrations in all 30 patients. In the eight patients who presented with fulminant hepatic failure, liver copper was quantitated from the explanted liver after the patient had undergone hepatic transplantation, or at autopsy. In an additional four patients who presented with non-fulminant liver disease, liver copper was not quantitated until the time of liver transplantation.

\section{Results}

Thirty patients with Wilson's disease were diagnosed between 1971 and 1998. Tables 1 and 2 summarise the main presenting clinical features, biochemical findings, and liver histology of these patients ( 15 men, 15 women). The mean age at diagnosis was 21 years; however, the age range was wide ( $7-58$ years) and five patients were over 40. Seventy per cent of patients were diagnosed within six months of their initial medical consultation; in the others there was a substantial delay of up to nine years.

\section{NON-FULMINANT PRESENTATION (22 PATIENTS)}

Diagnosis

Fourteen patients presented with liver abnormalities, three with neurological features, and one with haemolysis; four were asymptomatic siblings of patients with Wilson's disease (table 1). The indicators of abnormal copper metabolism pointing to the diagnosis were not present in all patients. Only 14 of the patients (64\%) had Kayser-Fleischer rings found; five patients had both Kayser-Fleischer rings and low caeruloplasmin concentrations, but normal urine copper excretion; two had KayserFleisher rings, high urine copper excretion, and normal caeruloplasmin concentrations; and seven patients had all three features present. Serum caeruloplasmin concentrations were low in $16(73 \%)$ and urine copper values were raised in 13 patients (59\%).

Of the six patients with normal caeruloplasmin values, four did not have Kayser-Fleischer rings (numbers 4, 19, 20, and 22). Two of these four (numbers 20 and 22) also had normal urine copper excretion-that is, they had no indicator of abnormal copper metabolism. Patient 20 required prompt transplantation and the diagnosis was established from the copper content of the liver explant; patient 22 had a positive radiolabelled copper plasma clearance test and the diagnosis was confirmed by measuring the liver copper content following transplantation for end stage liver disease with encephalopathy. Kayser-Fleischer rings were absent in three further patients (numbers 16,17 , and 18) who were asymptomatic siblings of index patients identified during 
Table 2 Patient details: fulminant hepatic failure

\begin{tabular}{|c|c|c|c|c|c|c|c|c|}
\hline Patient no & $\begin{array}{l}\text { Age at } \\
\text { diagnosis (y), } \\
\text { sex }\end{array}$ & $\begin{array}{l}\text { Non-caeruloplasmin } \\
\text { copper }(\mu \mathrm{g} / \mathrm{l}) \boldsymbol{q}\end{array}$ & $\begin{array}{l}\text { Caeruloplasmin } \\
(\mathrm{g} / \mathrm{l})\end{array}$ & $\begin{array}{l}\text { Liver } \\
\text { coppert } \\
(\mu g / g)\end{array}$ & $\begin{array}{l}\text { Radiocopper } \\
\text { study }\end{array}$ & $\begin{array}{l}\text { Kayser-Fleischer } \\
\text { rings }\end{array}$ & $\begin{array}{l}\text { Urine copper } \neq \\
(\mu g / 24 h)\end{array}$ & Histology \\
\hline 23 & $11, \mathrm{~F}$ & 462 & 0.08 & 380 & - & Present & - & Cirrhosis \\
\hline 24 & $12, \mathrm{~F}$ & - & Low\$ & 1100 & - & Present & - & Cirrhosis \\
\hline 25 & $15, \mathrm{~F}$ & 925 & 0.15 & 1847 & - & Present & 6437 & Cirrhosis \\
\hline 26 & $15, \mathrm{~F}$ & - & Low $\$ & 420 & - & Absent & - & Cirrhosis \\
\hline 27 & $16, \mathrm{~F}$ & 1743 & 0.21 & 767 & - & Present & 9375 & Cirrhosis \\
\hline 28 & $18, M$ & 500 & 0.09 & 600 & - & Present & 844 & Cirrhosis \\
\hline 29 & $44, \mathrm{~F}$ & 1330 & 0.14 & 717 & - & Absent & - & Cirrhosis \\
\hline 30 & $54, \mathrm{~F}$ & 325 & 0.18 & 1526 & - & Present & 2268 & Cirrhosis/CAH \\
\hline
\end{tabular}

*Normal caeruloplasmin $0.2-0.45 \mathrm{~g} / \mathrm{l}$; †normal liver copper $15-60 \mu \mathrm{g} / \mathrm{g}$ dry weight liver; $\ddagger$ normal urine copper less than $100 \mu \mathrm{g} / 24 \mathrm{~h}$; $\$$ caeruloplasmin quantitated in optical density units; Inormal non-caeruloplasmin copper less than $375 \mu \mathrm{g} / \mathrm{l}$, could not be quantitated in two patients as caeruloplasmin measured in OD units.

C/W WD: radiocopper study consistent with the diagnosis of Wilson's disease; CAH, chronic active hepatitis; FHF, fulminant hepatic failure.

family screening; all had low serum caeruloplasmin concentrations, but only patient 18 had an increased urine copper excretion.

Liver copper content was measured at the initial diagnostic liver biopsy in all but four patients (numbers 2, 10,19, and 20) in whom it was delayed until liver transplantation. In three of these four, the presumptive diagnosis was Wilson's disease, but in one (number 20) the aetiology of the liver disease was uncertain and was only established on examination of the explanted liver. This patient presented with end stage liver disease requiring prompt transplantation. There were no biochemical or histological features to suggest a cholestatic aetiology of the liver disease as an alternate cause for increased liver copper content. The histology of the cirrhosis included normal bile ducts, mild inflammatory activity, Mallory's hyaline, and copper binding protein in some peripheral hepatocytes. All patients had liver dry weight copper content in the range diagnostic of Wilson's disease (greater than $250 \mu \mathrm{g} / \mathrm{g}$ dry liver) except patient 19 , who had undergone six years of penicillamine treatment prior to liver transplantation, when the liver copper concentration was first measured. The diagnosis in this patient rested on an abnormal ${ }^{64} \mathrm{Cu}$ plasma disappearance and increased urine copper excretion.

Liver histology showed established cirrhosis in 11 patients, with concurrent chronic hepatitis in one; fibrosis in nine patients, with chronic hepatitis in three; and chronic hepatitis without fibrosis in two patients. There did not seem to be any relation between the age of the patient and the degree of progression to cirrhosis.

In addition to the three patients who presented with primary neurological features (numbers 7, 11, and 12), a further three (numbers 5,9 , and 14 ), whose primary presentation was non-neurological, were also noted to have mild neurological features (tremor, mild dysarthria, and a spastic gait respectively).

Management and outcome

All patients except number 20 were treated with penicillamine, which was for the most part well tolerated. Non-compliance with drug therapy was a problem in only one patient (number 16).

The longer term outcomes were generally good. Only one of the 22 patients (number 9) has died and this was prior to the availability of liver transplantation. This patient died with bacterial peritonitis, disseminated intravascular coagulation, and septic shock after being unwell for six months. Six patients who progressed to end stage liver disease have been successfully transplanted (mean follow up six years). The remaining 15 patients are clinically well and have not progressed to end stage cirrhosis during a mean follow up time of 16.4 years (range 2-25 years).

One of the six patients with neurological manifestations died soon after diagnosis (number 9). None of the other five have shown significant neurological improvement subsequently, despite the fact that they have all been treated for 15 or more years. In one case the neurological symptoms were intrusive enough to consider liver transplantation, but this was declined by the patient given the low probability of reversing long standing neurological changes.

FULMINANT HEPATIC FAILURE (EIGHT PATIENTS) Diagnosis

Eight patients (numbers 23-30) presented with fulminant hepatic failure. Six had KayserFleischer rings present and seven had low serum caeruloplasmin concentrations (table 2); five patients (numbers 23, 24, 25, 28, and 30) had both features present. Urine copper excretion was high in four patients (numbers $25,27,28$, and 30); the other four patients had become anuric. A high non-caeruloplasmin copper (greater than $375 \mu \mathrm{g} / \mathrm{l}$ ) was found in patients 23, 25, 27, 28, and 29 .

A probable diagnosis of Wilson's disease was established in all eight patients without a liver biopsy being attempted, as all had a severe coagulopathy. Subsequent examination of the liver, either at autopsy or following transplantation, showed that in all eight patients the liver was cirrhotic and the liver copper concentration was greater than $250 \mu \mathrm{g} / \mathrm{g}$ dry weight of liver (range 380-1847 $\mu \mathrm{g} / \mathrm{g}$ ).

In all patients alanine aminotransferase (ALT) activity was only moderately if at all raised (range 26-384 U/1); the same was true of alkaline phosphatase (ALP) activity (range 16-130 U/1).

Six patients (numbers 23, 25, 26, 27, 28, and 29) showed evidence of haemolysis, as indicated by a low haematocrit in the absence of blood loss, low plasma haptoglobin concentrations, and a raised reticulocyte count.

\section{Management and outcome}

Five patients (numbers 23, 24, 25, 26, and 29) presented before the availability of liver trans- 
plantation, and all five succumbed. In four of the five patients severe sepsis was the terminal event; the fifth died in liver failure. The other three patients underwent transplantation. One (number 27) died owing to primary graft failure; the other two (numbers 28 and 30) are alive and well six months and five years, respectively, after transplantation.

\section{Discussion}

In 1985, the abnormal gene in Wilson's disease was assigned to the long arm of chromosome $13^{14}$ and in 1993 it was identified and cloned. ${ }^{23}$ The Wilson's disease protein, designated ATP7B, seems to be a copper transporting P type ATPase which is presumed to transport copper across cell membranes, although its precise location and function in the hepatocyte are unknown. ${ }^{23}$ In contrast to haemochromatosis, where the vast majority of cases can be identified by a readily available laboratory test for the one or two key mutations of the haemochromatosis gene (HFE), ${ }^{15}$ Wilson's disease remains potentially difficult to diagnose. We must still rely on a constellation of clinical features and laboratory tests rather than a single test for the abnormal gene. This is because ATP7B can be affected by mutations at many sites; approximately 70 have been identified to date in patients with Wilson's disease, ${ }^{4}$ and it is likely that many more remain to be documented. Moreover, individual patients may carry two different mutations, one on each of the pair of chromosomes.

In the present study, the principal criteria pointing to a diagnosis of Wilson's disease in patients with suggestive hepatic and/or neurological clinical features were the presence of Kayser-Fleischer rings, a low serum caeruloplasmin, and a raised urinary copper excretion. In patients with non-fulminant presentations, the combination of Kayser-Fleischer rings and a low serum caeruloplasmin virtually establishes the diagnosis of Wilson's disease. ${ }^{1}$ This combination was present in only 12 of our 22 patients $(55 \%)$ with non-fulminant presentations; the other $10(45 \%)$ required further consideration before the diagnosis was regarded as established. In nine of these 10 patients estimation of liver copper concentration established the diagnosis of Wilson's disease. In patient 19, who had a normal serum caeruloplasmin and no Kayser-Fleischer rings, the diagnosis rested primarily on a characteristic ${ }^{64} \mathrm{Cu}$ plasma disappearance curve and a high urine copper excretion. After six years of continuous penicillamine treatment, the patient developed liver decompensation and received a liver transplant. The explanted liver was found to be cirrhotic, but the liver copper content normal. This may have reflected a sampling error, ${ }^{16}$ as it is unusual for penicillamine treatment to restore liver copper concentrations to normal. ${ }^{17}$

Caeruloplasmin concentrations were measured initially by the oxidase method and then subsequently by immunoprecipitation methods. All patients had low caeruloplasmin concentrations when measured by the oxidase method, which recognises only the copper containing form of caeruloplasmin; whereas 18 of 25 patients $(72 \%)$ had low caeruloplasmin values using the immunoprecipitation method, which may recognise not only blue copper containing caeruloplasmin but also colourless apocaeruloplasmin. ${ }^{18}$ Thus a true low caeruloplasmin may be missed owing to the immunoprecipitation methodology giving a falsely high value, a point discussed by Steindl et al in their series $^{5}$ and in the accompanying editorial. ${ }^{18}$

In fulminant hepatic failure patients, the diagnosis of Wilson's disease can be particularly difficult. Kayser-Fleischer rings may be absent, ${ }^{519}$ and caeruloplasmin concentrations may either be falsely raised, as it is an acute phase reactant, or low, owing to liver cell failure from other causes. ${ }^{20}$ Liver biopsy may not be readily obtainable. Diagnosis will be assisted by the finding of a Coombs negative haemolytic anaemia, ${ }^{21}$ a high non-caeruloplasmin copper concentration, ${ }^{19}$ and greatly increased urine copper excretion. ${ }^{6}$ A further pointer to the diagnosis in fulminant hepatic failure patients is that the ALT and ALP are only slightly raised, ${ }^{19}$ as seen in our patients. These ALT concentrations contrast sharply with those normally found in fulminant hepatic failure owing to viruses, drugs, or toxins. Despite the potential diagnostic difficulties, all of our eight patients had features that allowed the clinical diagnosis of Wilson's disease to be made.

None of our patients underwent haplotype analysis to identify the particular mutations present or to help establish the diagnosis of Wilson's disease. Had such testing been available, it might have been helpful, particularly in determining the disease status in patients $4,16,17$, and 18 , who were asymptomatic siblings of index cases ${ }^{52}$ and who did not have Kayser-Fleischer rings. The diagnosis was suspected in three because they had low caeruloplasmin concentrations, and in the fourth because of an increased urine copper excretion and abnormal liver function tests; all four had substantially raised liver copper concentrations (table 1). It is possible that without haplotype analysis we may still have missed an asymptomatic sibling with no abnormal laboratory findings. ${ }^{5}$ We do not believe, however, that the risk of routine liver biopsy of siblings is justified if there is no clinical or biochemical evidence of Wilson's disease.

Steindl and colleagues ${ }^{5}$ have recently described the diagnostic challenges of Wilson's disease in 55 cases seen over a 29 year period from 1967. Although many of their patients were analysed (some in retrospect) for the His 1069 Gln mutation, which seems to be the commonest mutation in their country, it was of practical diagnostic help in only one case, a sibling who had no abnormal clinical or laboratory findings. She was found to be homozygous for the Wilson's disease gene, and a subsequent liver biopsy showed a 20 -fold increase in liver copper. ${ }^{23}$

As in the present study, Steindl's group ${ }^{5}$ had to rely on a careful clinical appraisal together with one or more laboratory findings, and it was apparent that patients presenting with 
hepatic abnormalities provided the greater diagnostic difficulty. For example, $90 \%$ of those with a neurological presentation had Kayser-Fleischer rings and $85 \%$ a low caeruloplasmin concentration; with a liver presentation, however, only $44 \%$ had Kayser-Fleischer rings and $60 \%$ a reduced caeruloplasmin concentration. Four patients were given a trial of penicillamine on the basis of a positive family history, increased urinary copper, or an increased but not diagnostic liver copper concentration. ${ }^{24}$ The authors considered that the diagnosis was established by a "favourable clinical response and high urinary copper excretion" following penicillamine treatment. In contrast to Steindl et al, we did not consider response to penicillamine treatment as a diagnostic criterion. We believe it preferable to try to make a diagnosis at the outset, given the implications for the family and the need for lifelong treatment of the patient, and we agree with Schilsky and Sternlieb, ${ }^{18}$ that a trial of penicillamine will usually not resolve a diagnostic dilemma. Further tests such as ${ }^{64} \mathrm{Cu}$ disappearance or transjugular liver biopsy will help to achieve greater diagnostic certainty in the difficult patient in whom abnormal coagulation precludes a conventional biopsy. We consider the algorithm presented by Steindl and colleagues $^{5}$ for the investigation and diagnosis of Wilson's disease is a useful guide. Our contention is that liver biopsy with quantititative copper quantitation remains the "gold standard" for the diagnosis.

It has been widely accepted that most patients develop symptoms between the ages of five and 30, and that neurological presentations tend to occur in the over twenties. ${ }^{25}$ In the present study, the patients presenting with neurological features were 12,17 , and 19 years old. More importantly, seven of our 30 patients were 30 and over, the oldest being 58; these seven patients presented without neurological disease. Three of the seven (numbers 18, 21, and 22) had not progressed to cirrhosis. It may prove to be that the type and extent of the defect in the gene determines the age of onset of the disease, ${ }^{26}$ but this remains to be established. It does seem, however, that the His 1069 Gln mutation is associated with later onset disease. ${ }^{26}$ Our findings along with those of others, ${ }^{510}$ alert clinicians that Wilson's disease may present in patients well above 30 years of age.

Wilson's disease remains, on occasion, a difficult diagnosis to establish. While haplotype analysis may be helpful in identifying a homozygote patient with Wilson's disease when screening the siblings of an index case, it is not yet helpful in de novo diagnosis, given the large number of mutations that may be present. Reliance still must be placed on a high index of clinical suspicion which will lead to the appropriate investigations being carried out. There is no one test which is completely reliable, but the diagnosis can usually be established or ruled out provided that someone thinks of it.

1 Sternlieb I. Perspectives on Wilson's disease. Hepatology 1990;12:1234-9.

2 Tanzi RE, Petrukhin K, Chernov I, et al. The Wilson disease gene is a copper transporting ATPase with homology to the Menkes disease gene. Nat Genet 1993;5:344-50.

3 Bull PC, Thomas GR, Rommens JM, et al. The Wilson disease gene is a putative copper transporting P-type ATPase similar to the Menkes gene. Nat Genet 1993;5:327-37.

4 Shah AB, Chernov I, Zhang HT, et al. Identification and analysis of mutations in the Wilson's disease gene (ATP7B): population frequencies, genotype-phenotype correlation, and functional analyses. Am $\mathcal{F} \mathrm{Hum}$ Genet 1997;61:317-28.

5 Steindl P, Ferenci P, Dienes HP, et al. Wilson's disease in patients presenting with liver disease: a diagnostic challenge. Gastroenterology 1997;113:212-18.

6 McCullough AJ, Fleming CR, Thistle JL, et al. Diagnosis of Wilson's disease presenting as fulminant hepatic failure. Gastroenterology 1983;84:161-7.

7 Stremmel W, Meyerrose KW, Niederau C, et al. Wilson's disease: clinical presentation, treatment, and survival. Ann Intern Med 1991;115:720-6.

8 Sternlieb I, Scheinberg IH. Wilson's disease. In: Mcintyre N, Benhamou JP, Bircher J, et al, eds. Oxford textbook of clinical hepatology. Oxford: Oxford University Press, 1991: 945-8.

9 Sternlieb I, Scheinberg IH. The role of radiocopper in the diagnosis of Wilson's disease. Gastroenterology 1979;77: 138-42.

10 Danks D, Metz R, Sewell R, et al. Wilson's disease in adults with cirrhosis but no neurological abnormalities. BMf 1990;301:331-2.

11 Sternberg JC. Rate nephelometer for measuring specific proteins by immunoprecipitin reactions. Clin Chem 1977; 23:1456-64.

12 Rosenberg EB, Strickland GT, Feng YS. Comparison of immunologic and enzymatic methods for ceruloplasmin quantitation in Wilson's disease. Taiwan I Hsueh Hui Tsa quantitation in Wilson's

13 Kingston HM, Jassie LB. Microwave energy for acid decomposition at elevated temperatures and pressures using biological and botanical samples. Anal Chem $1986 ; 58: 2534-41$

14 Frydman M, Bonne-Tramir B, Farrer LA, et al. Assignment of the gene for Wilson disease to chromosome 13: linkage to the esterase D locus. Proc Natl Acad Sci USA 1985;82:1819-21.

15 Adams PC, Campion ML, Gandon G, et al. Clinical and family studies in genetic hemochromatosis: microsatellite and HFE studies in five atypical families. Hepatology 1997; 26:986-90.

16 McDonald JA, Snitch P, Painter D, et al. Striking variability of hepatic copper levels in fulminant hepatic failure. $\mathcal{f}$ Gastroenterol Hepatol 1992; 7:396-8.

17 Mason J, McQuaid A, Pheiffer H. Can patients with Wilson's disease be decoppered? Lancet 1989;i:1455.

18 Schilsky ML, Sternlieb I. Overcoming obstacles to the diagnosis of Wilson's disease. Gastroenterology 1997;113:350-3.

19 Berman DH, Leventhal RI, Gavaler JS, et al. Clinical differentiation of fulminant Wilsonian hepatitis from other causes of hepatic failure. Gastroenterology 1991;100:112934

20 Walshe JM, Briggs J. Caeruloplasmin in liver disease: a diagnostic pitfall. Lancet 1962;ii:263-5.

21 Iser JH, Stevens BJ, Stening GF, et al. Hemolytic anemia of Wilson's disease. Gastroenterology 1974;67:290-3.

22 Houwen RH, Roberts EA, Thomas GR, et al. DNA markers for the diagnosis of Wilson's disease. F Hepatol 1993;17: 269-76.

23 Maier-Dobersberger T, Mannhalter C, Rack S, et al. Diagnosis of Wilson's disease in an asymptomatic sibling by DNA linkage analysis. Gastroenterology 1995;109:201518 .

24 DaCosta CM, Baldwin D, Portmann B. Value of urinary copper excretion after penicillamine challenge in the diag nosis of Wilson's disease. Hepatology 1992;15:609-15.

25 Strickland GT, Frommer D, Leu ML, et al. Wilson's disease in the United Kingdom and Taiwan. I. General characetristics of 142 cases and prognosis. II. A genetic analysis of 88 cases. Qf Med 1973;42:619-38.

26 Thomas GR, Forbes JR, Roberts EA, et al. The Wilson disease gene: spectrum of mutations and their consequences. Nat Genet 1995;9:210-17. 